\title{
Basic helix-loop-helix transcription factor DEC2 functions as an anti-apoptotic factor during paclitaxel-induced apoptosis in human prostate cancer cells
}

\author{
QIANG LIU ${ }^{1,2}$, YUNYAN WU ${ }^{1}$, TADASHI YOSHIZAWA ${ }^{1}$, XU YAN $^{1}$, SATOKO MOROHASHI $^{1}$, \\ HIROKO SEINO $^{1}$, YUKIO KATO ${ }^{3}$ and HIROSHI KIJIMA ${ }^{1}$ \\ ${ }^{1}$ Department of Pathology and Bioscience, Hirosaki University Graduate School of Medicine, \\ Hirosaki, Aomori 036-8562, Japan; ${ }^{2}$ Department of Nephrology, the First Hospital of \\ China Medical University, Shenyang 110001, P.R. China; ${ }^{3}$ Department of Dental and Medical Biochemistry, \\ Hiroshima University Graduate School of Biomedical Science, Hiroshima 734-8553, Japan
}

Received March 31, 2016; Accepted August 24, 2016

DOI: $10.3892 / \mathrm{ijmm} .2016 .2798$

\begin{abstract}
The functions of basic helix-loop-helix (bHLH) transcription factor-differentiated embryonic chondrocyte (DEC)1 (BHLHE40) and 2 (BHLHE41) are involved in various fields such as circadian rhythms, immune responses, cell proliferation, hypoxia reaction as well as malignant tumors. Previous findings showed that DEC served as apoptosis regulators of various cancer cell lines. However, little is known regarding the expression of DEC1 and DEC2 in prostate cancer cells. The present study aimed to examine the roles of DEC1 and DEC2 in human prostate cancer DU145 and PC-3 cells that were treated with paclitaxel. The expression of DEC1 and DEC2 was decreased in DU145 cells but was increased in PC-3 cells when treated with paclitaxel. DU145 cells were more sensitive to paclitaxel than PC-3 cells since the amount of cleaved poly(ADP-ribose) polymerase (PARP) reached its peak at $50 \mu \mathrm{M}$ of paclitaxel in DU145 cells but at $100 \mu \mathrm{M}$ in PC-3 cells. In addition, the amount of cleaved PARP was decreased by DEC1 siRNA, while it was increased by DEC2 siRNA in the presence of paclitaxel. Although DEC2 overexpression slightly inhibited cleaved PARP in the two cell lines, the effects of DEC1 overexpression on apoptosis remain to be determined. In conclusion, $\mathrm{DEC1}$, at least partly, exerted a pro-apoptotic effect, whereas
\end{abstract}

Correspondence to: Dr Yunyan Wu, Department of Pathology and Bioscience, Hirosaki University Graduate School of Medicine, 5 Zaifu-cho, Hirosaki, Aomori 036-8562, Japan

E-mail: yunyanwu@hirosaki-u.ac.jp

Abbreviations: DEC1, differentiated embryonic chondrocyte 1; DEC2, differentiated embryonic chondrocyte 2; PARP, poly (ADP-ribose) polymerase; CRPC, castration-resistant prostate cancer

Key words: DEC1, DEC2, paclitaxel, prostate cancer, DU145 cells, PC-3 cells
DEC2 exerted an anti-apoptotic effect in paclitaxel-induced apoptosis of human prostate cancer cells.

\section{Introduction}

Prostate cancer remains among the most frequently diagnosed solid tumors in men. According to the latest cancer statistics, prostate cancer accounts for $27 \%$ of all cancer incidences and ranks the second leading cause of cancer-related mortality among men in the United States (1). Although androgen deprivation therapy is initially effective for treating localized and androgen responsive prostate cancer, most patients relapse due to the development of castration-resistant prostate cancer (CRPC) after 2-3 years (2). Treatment options for castration-resistant prostate cancer are limited and often associated with significant morbidity and mortality. Mitoxantrone plus prednisone were initially identified as the standard chemotherapy for hormone-refractory prostate cancers until the drug taxane was applied for treatment. Based on a simultaneous publication of two large randomized control trials, Tannock et al showed that combined taxane drugs and prednisone can significantly prolong survival in men with hormone-refractory prostate cancer $(3,4)$.

Paclitaxel is one of the typical taxane drugs and is also a well-studied chemotherapeutic agent. Paclitaxel stabilizes guanosine diphosphate (GDP)-bound tubulin to prevent the depolymerization of microtubules, thereby terminating cell division. Paclitaxel has clinical efficacy in various types of cancer, including several refractory tumors such as ovarian carcinoma, acute myeloblastic leukemia, and CRPC (5-7). Specific mechanisms for paclitaxel inducing inhibition in cancer cells are considered to be mediated by the activation of c-Jun $\mathrm{N}$-terminal kinase (JNK), downregulation of Bcl-2/Bcl-xL and the activation of caspases and poly(ADP-ribose) polymerase PARP (8-11), resulting in the induction of apoptosis. It can also cause growth arrest at the G2/M phase of the cell cycle, leading to the promotion of cell apoptosis $(11,12)$.

Differentiated embryonic chondrocyte gene (DEC)1 and 2 are members of the basic helix-loop-helix (bHLH) 
superfamily of transcription factors that have been reported to be associated with cell proliferation, circadian rhythms, tumor progression, as well as the response to hypoxia (13-16). In a previous study, we showed that DEC1 and DEC2 have opposite properties in regulating apoptosis, i.e., DEC2 has anti-apoptotic, whereas DEC1 has pro-apoptotic effects on an estrogen receptor-positive cell line, MCF-7, when treated with paclitaxel (17). However, the roles of DEC1 and DEC2 in apoptosis induced by paclitaxel in CRPC are unknown.

In the present study, we investigated the effects of DEC1 and DEC2 on paclitaxel-induced apoptosis of DU145 and PC-3 cells. The results demonstrated that DEC1 has proapoptotic effects, and DEC2 has anti-apoptotic effects on paclitaxel-treated DU145 and PC-3 cells.

\section{Materials and methods}

Cell culture and treatment. The DU145 and PC-3 human prostate cancer cells were purchased from RIKEN BRC through the National Bio-Resource Project of the MEXT (Japan). The cells were cultured in RPMI-1640 medium supplemented with $10 \%$ fetal bovine serum at $37^{\circ} \mathrm{C}$ in a humidified atmosphere of $95 \%$ air and $5 \% \mathrm{CO}_{2}$. In some experiments, the cells were incubated with various concentrations of paclitaxel (Calbiochem, San Diego, CA, USA) for 24,48 or $72 \mathrm{~h}$.

Knockdown of DEC1 or DEC2 by RNA interference. Short interference RNA (siRNA) against DEC1 or DEC2 were synthesized by Qiagen (Mississauga, ON, Canada). The sequences of DEC1, DEC2, and the negative control siRNA were described previously (18). For the siRNA transfection experiments, $5 \times 10^{4}$ cells of DU145 or PC-3 cells were seeded per 35-mm well. SiRNAs were transfected into the cells $24 \mathrm{~h}$ later using the Lipofectamine RNA iMAX reagent (Invitrogen, Carlsbad, CA, USA). After transfection, the cells were incubated for another $24 \mathrm{~h}$ and subjected to western blot analysis.

DEC1 and DEC2 overexpression. Human DEC1 and DEC2 plasmids were a kind gift from Dr Katsumi Fujimoto (Hiroshima University) (14). DU145 or PC-3 cells $\left(5 \times 10^{4}\right)$ were seeded per $35-\mathrm{mm}$ well. DEC1 or DEC2 plasmid was transiently transfected into the cells $24 \mathrm{~h}$ later using the Lipofectamine LTX reagent (Invitrogen). Following transfection, the cells were incubated with paclitaxel for another $24 \mathrm{~h}$ and then subjected to western blot analysis.

Reverse transcription-quantitative polymerase chain reaction $(R T-q P C R)$. Three independent RNA samples $(\mathrm{n}=3)$ from DU145 and PC-3 cells were prepared for RT-PCR. Total RNA was isolated using an RNeasy RNA isolation kit (Qiagen). First-strand cDNA was synthesized from $1 \mu \mathrm{g}$ of total RNA using ReverTra Ace (Toyobo Co., Ltd., Osaka, Japan). PCR was carried out using Taq PCR Master mix (Qiagen). The primer sequences used were: DEC1 F, 5'-GTCTGTGAGTCA CTCTTCAG-3' and R, 5'-GAGTCTAGTTCTGTTTGA AGG-3'; DEC2 F, 5'-CACCTTTGACGTCTTTGGAG-3' and R, 5'-GAGAGTGGGAATAGATGCAC-3' and GAPDH F, 5'-CCACCCATGGCAAATTCCATGGCA-3' and R, 5'-AGA CCACCTGGTGCTCAGTGTAGC-3'. The amplified products of DEC1, DEC2 and GAPDH were 534, 502 and 696 bp in length, respectively. The cDNAs for DEC1 and DEC2 were amplified for $>27$ cycles, and those for GAPDH were amplified at 20 cycles. The PCR products were separated on $1.5 \%(\mathrm{w} / \mathrm{v})$ agarose gels.

Western blot analysis. Cells were lysed using M-PER lysis buffer (Thermo Scientific, Waltham, MA, USA), and their protein concentrations were determined using the bicinchoninic acid (BCA) assay. The obtained lysates (5 $\mu \mathrm{g}$ protein) were subjected to SDS-PAGE, and the separated proteins were transferred to PVDF membranes (Immobilon P, Millipore, Billerica, MA, USA), followed by immunoblot analysis utilizing the indicated antibodies. Signals were detected using Bio-Rad western blotting systems (Bio-Rad, Hercules, CA, USA) with the ECL-prime or ECL-select western blot analysis detection systems (GE Healthcare, Little Chalfont, UK).

Cell viability assay. The cells seeded in 96-well plate were cultured with different concentrations of paclitaxel for 24, 48 and $72 \mathrm{~h}$. In another experiment, the cells were initially transfected with the DEC2 overexpression plasmid and culture was continued in medium with $50 \mu \mathrm{M}$ paclitaxel for an additional $24 \mathrm{~h}$; the cells transfected with pcDNA without paclitaxel treatment were used as the control. Cell viability analysis was performed using the MTS [3-(4,5-dimethylthiazol-2-yl)-5-(3carboxymethoxyphenyl)-2-(4-sulfophenyl)-2H-tetrazolium] assay as described previously (19).

Statistical analysis. The results are presented as the means \pm standard error of the mean (SEM). Statistical analysis was performed using the Student's t-test. A value of $\mathrm{P}<0.05$ was considered to indicate statistically significant results.

\section{Results}

Effects of paclitaxel on DEC1 and DEC2 expression in DU145 and PC-3 cells. It is known that paclitaxel induces the apoptosis of various cancer cells. Thus, we examined the expression of apoptotic markers, as well as that of DEC1 and DEC2 in DU145 and PC-3 cells treated with 10, 20, 50 and $100 \mu \mathrm{M}$ of paclitaxel. The mRNA and protein levels of DEC1 and DEC2 were decreased in a dose-dependent manner in DU145 cells when treated with paclitaxel for $24 \mathrm{~h}$ (Fig. 1A, left panel), but were increased in PC-3 cells (Fig. 1B, left panel). In addition, paclitaxel increased the amount of cleaved PARP and cleaved caspase-8, but decreased that of Bcl-2 and Bcl-xL. However, the level of caspase-9, Bad, and Bax was not affected by paclitaxel in the two cell lines (Fig. 1A and B right panel).

Knockdown of DEC1 and DEC2 in the presence of paclitaxel has opposite effects on apoptotic markers in DU145 and PC-3 cells. DEC1 or DEC2 knockdown by siRNA significantly reduced the expression of DEC1 or DEC2, respectively (Fig. 2). Compared with DU145 or PC-3 cells transfected with control siRNA, paclitaxel-combined control siRNA induced the amount of cleaved PARP and cleaved caspase-8, which was decreased by DEC1 siRNA. On the other hand, the expression of Bcl-2 was downregulated by paclitaxel treatment, but was upregulated when DEC1 was knocked down (Fig. 2A and B). By contrast, DEC2 knockdown increased the amount of 
A

DU145 cells
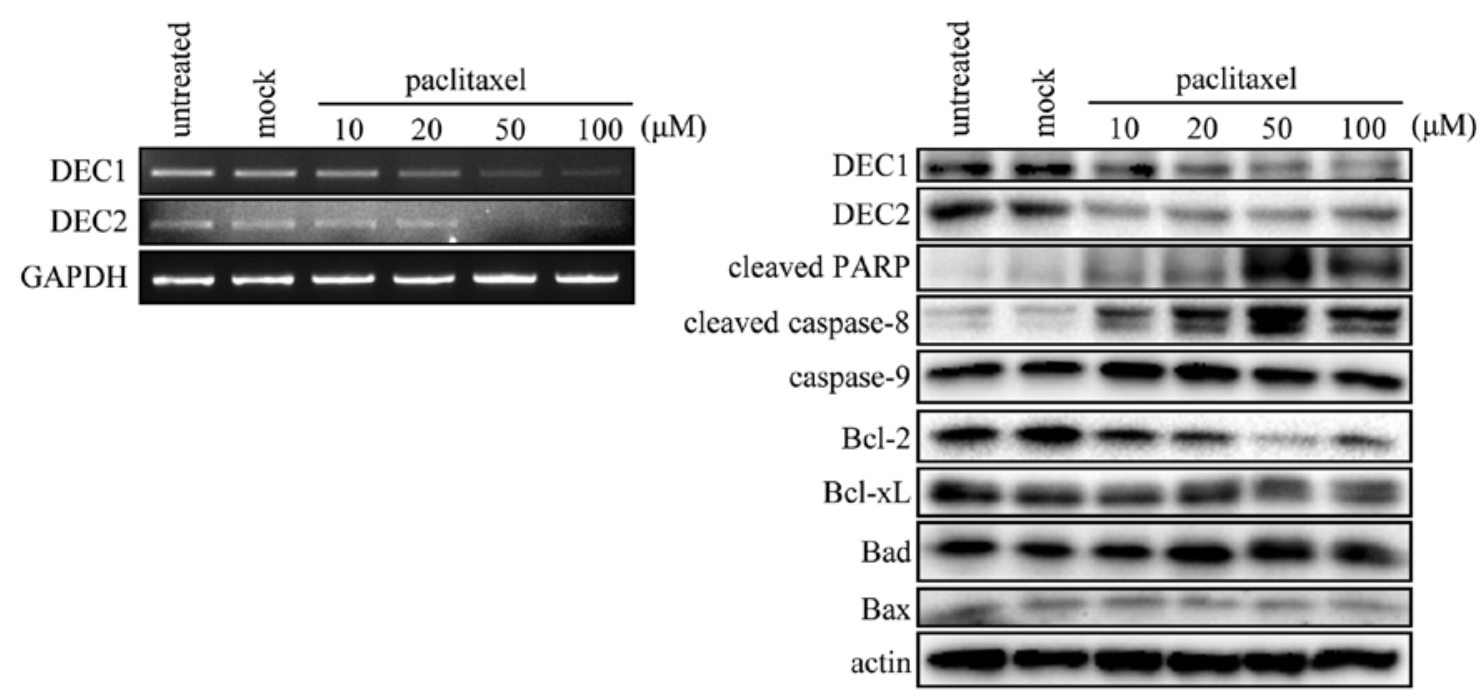

B

PC-3 cells
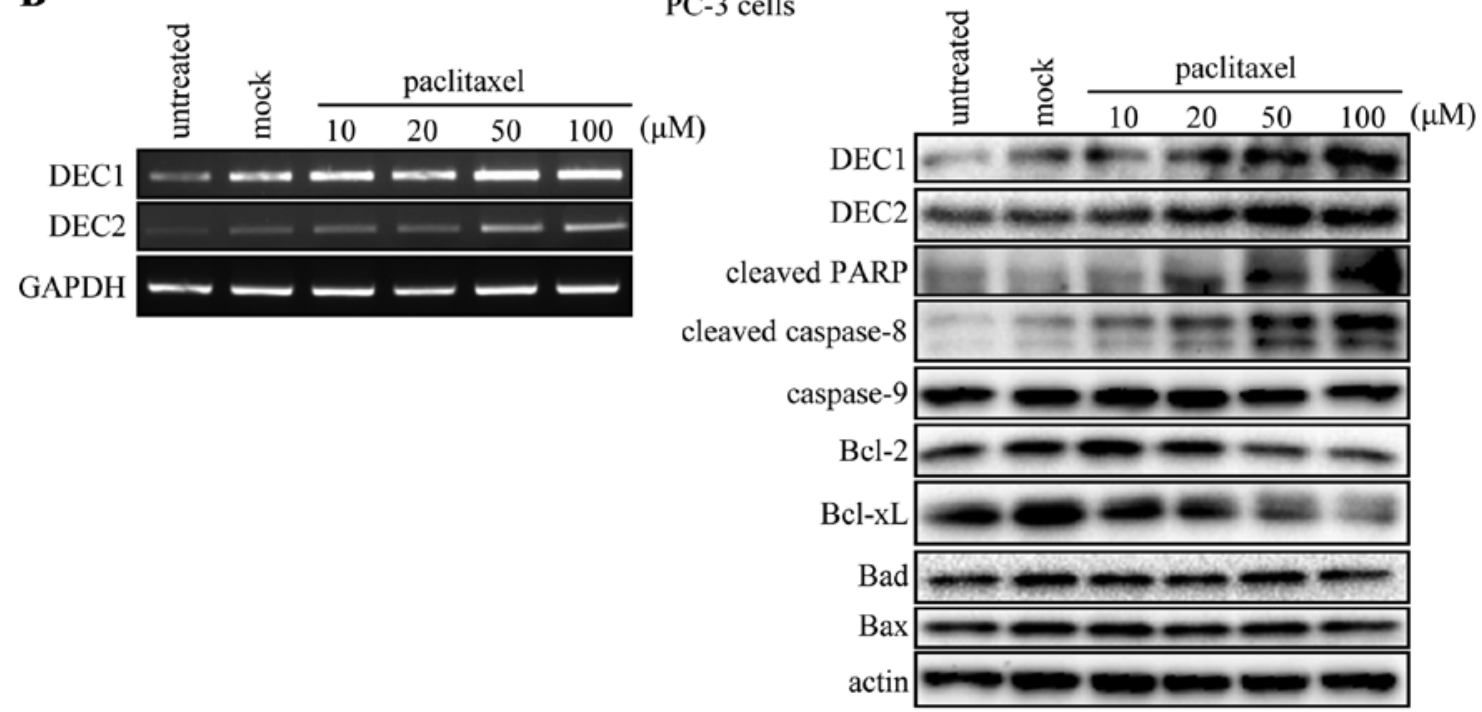

Figure 1. Paclitaxel affects the expression of DEC1 and DEC2. DU145 and PC-3 cells were treated with various concentrations of paclitaxel. After $24 \mathrm{~h}$, total RNA was prepared and subjected to RT-PCR analysis of DEC1, DEC2 and GAPDH (A and B, left panel). DU145 and PC-3 cells were treated with paclitaxel for $24 \mathrm{~h}$. The cells were lysed, and the lysates were subjected to western blot analysis of DEC1, DEC2, cleaved PARP, cleaved caspase-8, caspase-9, Bcl-2, Bcl-xL, Bad, Bax, and actin (A and B, right panel). DEC, differentiated embryonic chondrocyte ; PARP, poly (ADP-ribose) polymerase.

cleaved PARP and caspase-8, whether with or without paclitaxel (Fig. 2C and D). The expression of $\mathrm{Bcl}-2$, which was downregulated by paclitaxel treatment, was further inhibited when DEC2 was knocked down.

Overexpression of DEC1 or DEC2 has no effect on apoptotic markers in DU145 and PC-3 cells. Using transient transfection, we examined whether the overexpression of DEC1 or DEC2 affected the expression of apoptotic markers in DU145 and PC-3 cells. DEC1 and DEC2 overexpression in the presence or absence of paclitaxel $(50 \mu \mathrm{M})$ showed little effect on the expression of cleaved PARP, cleaved caspase- 8 , and Bcl-2 (Fig. 3).

DEC2 overexpression inhibits cell death in DU145 and PC-3 cells.Paclitaxel induced cell death in a time-and dose-dependent manner in DU145 and PC-3 cells using the MTS assay (Fig. 4). We also investigated whether DEC2 overexpression affected cell viability in these cells. DEC2 overexpression in the presence of paclitaxel $(50 \mu \mathrm{M})$ significantly increased the cell viability compared with that in paclitaxel-treated control cells. In addition, DEC2 overexpression in the absence of paclitaxel had little effect on the viability in these cells (Fig. 5).

\section{Discussion}

In the present study, we examined how DEC1 or DEC2 functions during apoptosis caused by the anti-cancer drug paclitaxel. Two of the well-characterized androgen-independent prostate cancer cell lines DU145 and PC-3, were selected in the present study as many prostate cancer patients showed androgen-independent growth. Paclitaxel-induced apoptosis in 
A

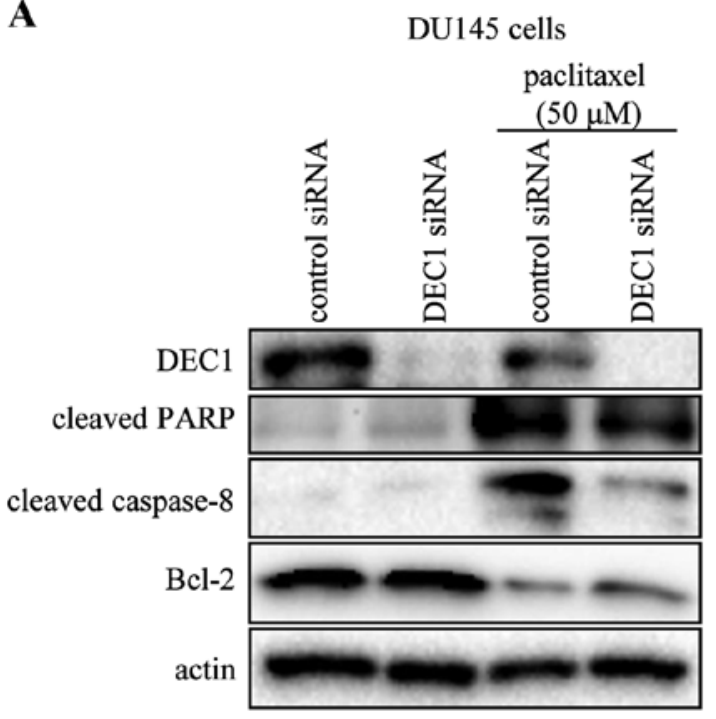

C

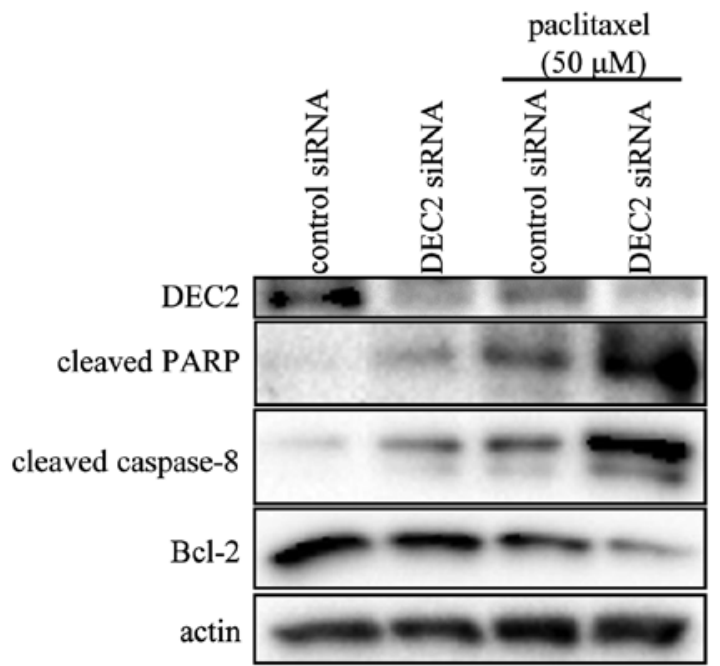

B

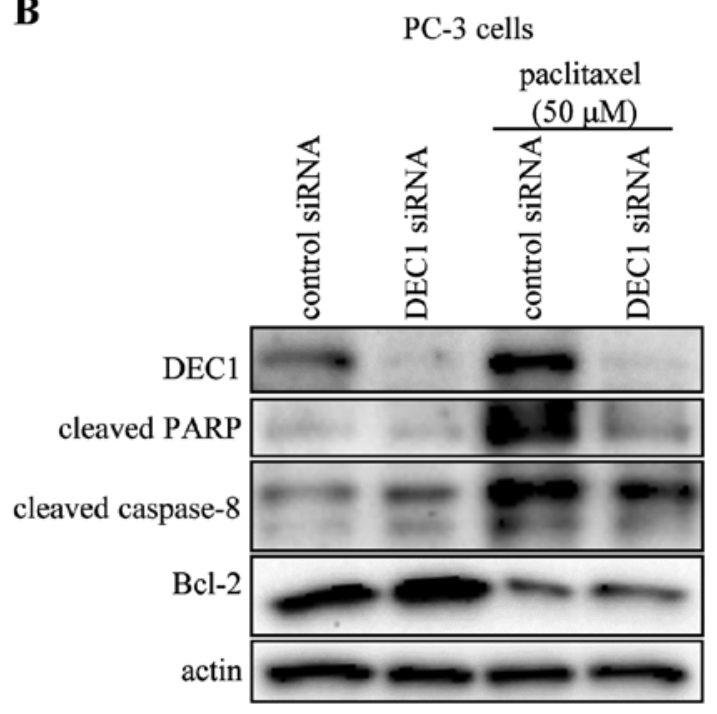

D

PC-3 cells

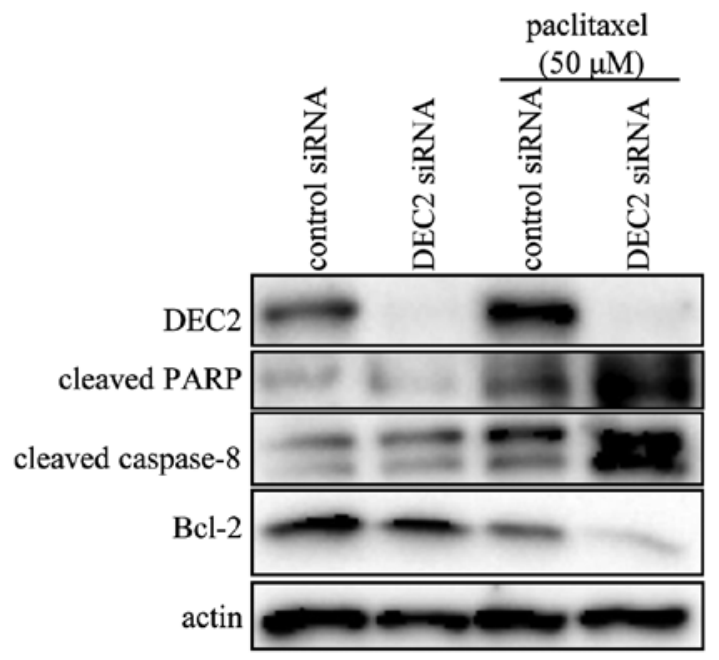

Figure 2. Analysis of apoptotic marker expression in DU145 and PC-3 cells by DEC1 or DEC2 knockdown. DU145 and PC-3 cells were transfected with DEC1 siRNA (A and B) or DEC2 siRNA (C and D) and incubated for $24 \mathrm{~h}$. Subsequently, the cells were incubated with or without paclitaxel (50 $\mu \mathrm{M})$ for another $24 \mathrm{~h}$. Cell lysates were prepared and subjected to western blot analysis of DEC1, DEC2, cleaved PARP, cleaved caspase-8, Bcl-2 and actin. One representative of at least three independent experiments with similar results is shown. DEC, differentiated embryonic chondrocyte; PARP, poly (ADP-ribose) polymerase.

the two cells, however, differential chemotherapeutic response was found between the two cells. Paclitaxel treatment $(50 \mu \mathrm{M})$ produced the largest amount of cleaved PARP in DU145 cells and $100 \mu \mathrm{M}$ was needed in PC-3 cells. Additionally, $>50 \%$ of DU145 cells died when cultured in $100 \mu \mathrm{M}$ of paclitaxel, which explains the relatively weaker band of cleaved-PARP obtained in these cells. Moreover, the viability of DU145 cells following paclitaxel treatment showed a more significant reduction than that of PC-3 cells. This difference may be caused by the status of a tumor suppressor gene, PTEN. Mutations or loss of expression of this gene was found in a high percentage of prostate cancer patients. Lee et al showed that PC-3 was a PTEN-negative cell line, while DU145 was a PTEN-positive cell line (20). On the other hand, the expression of apoptotic markers, as well as DEC was differentially regulated in the two cell lines. Thus, DEC1 and DEC2 were decreased by paclitaxel in DU145 cells but increased in PC-3 cells. Previous studies showed that DEC1 and DEC2 were regulated by many environmental and endogenous factors in various cell lines (21-24). Changes of DECs were dependent on the cell lines and the types of reagents, or even the amount of the reagents applied. The function of paclitaxel on DEC in the breast MCF-7 adenocarcinoma cell line has been previously discussed (17). In MCF-7 cells, the expression of DEC1 and DEC2 was increased by paclitaxel in a dose-dependent manner. Additionally, the extent of DEC2 upregulation was much higher than that of DEC1. In another report, we analyzed the effect of DEC during cisplatin-induced apoptosis (25). Cisplatin decreased DEC1 and DEC2 in an oral squamous carcinoma CA9-22 cell line, but DEC1 and DEC2 were not directly associated with apoptosis in this cell line. By contrast, in HSC-3, another oral squamous carcinoma cell line, cisplatin increased 
A

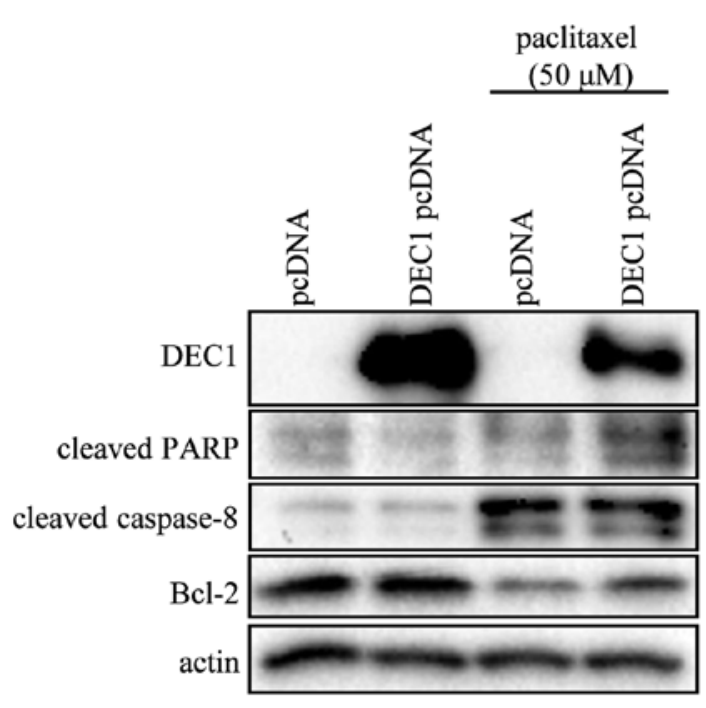

C

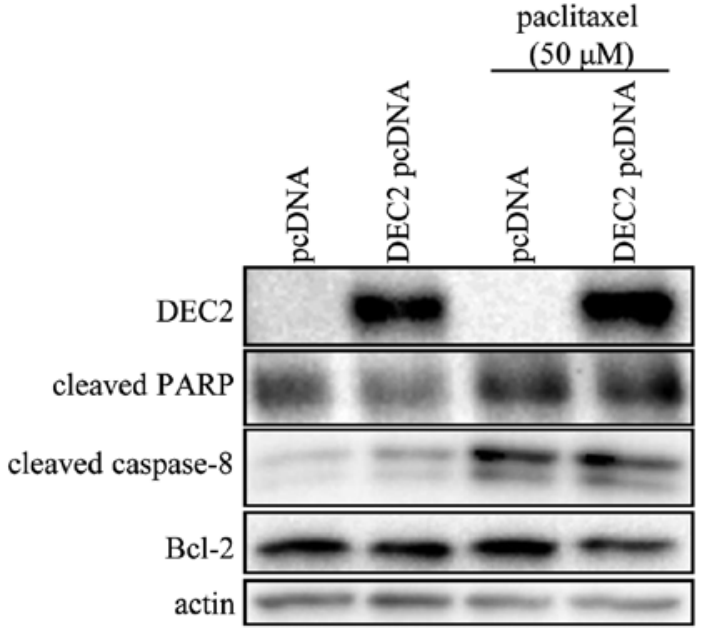

B

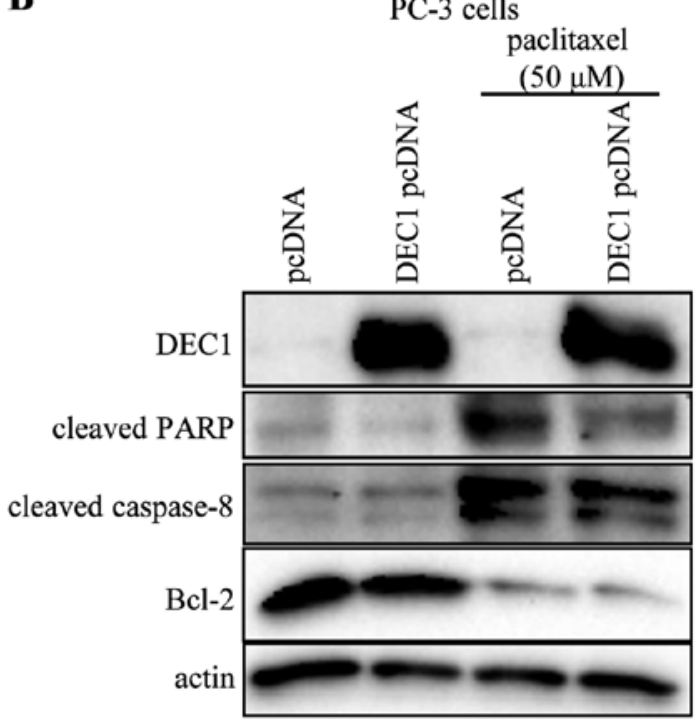

D

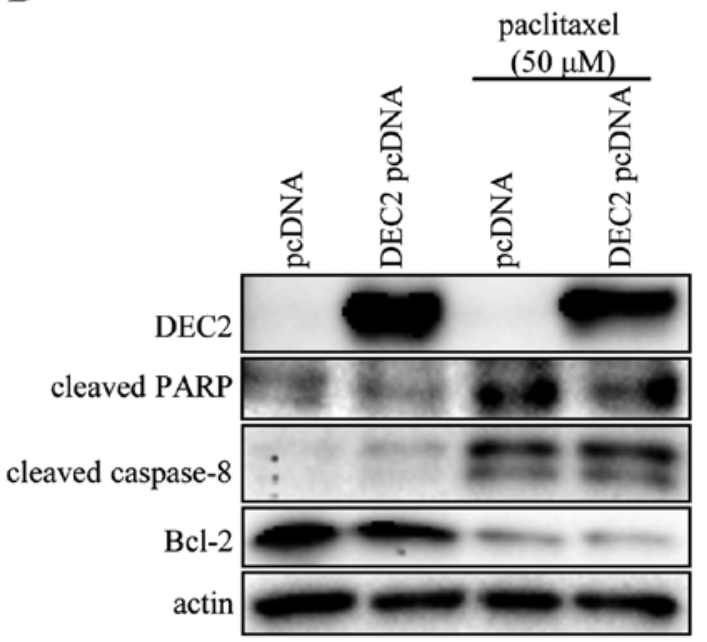

Figure 3. Overexpression of DEC1 or DEC2 has no effect on the expression of apoptotic markers in DU145 and PC-3 cells. DU145 and PC-3 cells were transfected with DEC1 pcDNA (A and B) or DEC2 pcDNA (C and D) and incubated for $24 \mathrm{~h}$. The cells were treated with paclitaxel $(50 \mu \mathrm{M})$ and incubated for an additional $24 \mathrm{~h}$, before being lysed. The lysates were subjected to western blot analysis of DEC1, DEC2, cleaved PARP, cleaved caspase-8, Bcl-2 and actin. One representative of at least three independent experiments with similar results is shown. DEC, differentiated embryonic chondrocyte; PARP, poly (ADP-ribose) polymerase.

DEC2, which inhibited apoptosis by regulating Bim protein. Although a similar protein structure exists in DEC1 and DEC2, it is better to consider them distinctly when referring to their functions. For example, DEC2 was usually identified as an apoptosis inhibitor whereas the role of DEC1 in apoptosis is under debate $(16,17)$. Another report suggested that DEC1 was induced but DEC2 was reduced when PANC-1 cells were exposed to transforming growth factor (TGF)- $\beta$ (26). In addition, DEC1 exerted its effect on transcription factors that subsequently regulated the epithelial-mesenchymal molecules to progress the epithelial-mesenchymal transition (EMT) of carcinoma cells, whereas DEC2 did not exert such an effect. As effectors of hypoxia, DEC1 response was more rapid to hypoxic stress than DEC2. Previous findings showed that the upregulation of DEC2 in the latter stage of hypoxia accompanied with the increase in cell proliferation led to oxygen-deprived stress (19).
In the present study, DU145 and PC-3 cells transfected with DEC1 siRNA under paclitaxel treatment showed decreased levels of cleaved PARP and cleaved caspase-8, but an increased level of anti-apoptotic factor Bcl-2 when compared with the control siRNA-transfected cells. However, DEC2 siRNA-transfected cells exhibited opposite results to those mentioned above. Since DEC1 or DEC2 functioned similarly in regulating apoptosis but showed a distinct response to paclitaxel in DU145 and PC-3 cells, the key factor in modulating apoptosis was considered to be different in the two cell lines. In addition to the knockdown analyses, overexpression experiments were also applied in the present study and a weak downregulation of cleaved PARP as well as a slight upregulation in cell viability by DEC2 overexpression were obtained in the two cell lines, although significant changes of cleaved caspase- 8 and Bcl-2 were not found. On the other hand, DEC1 overexpression had 
$\mathbf{A}$

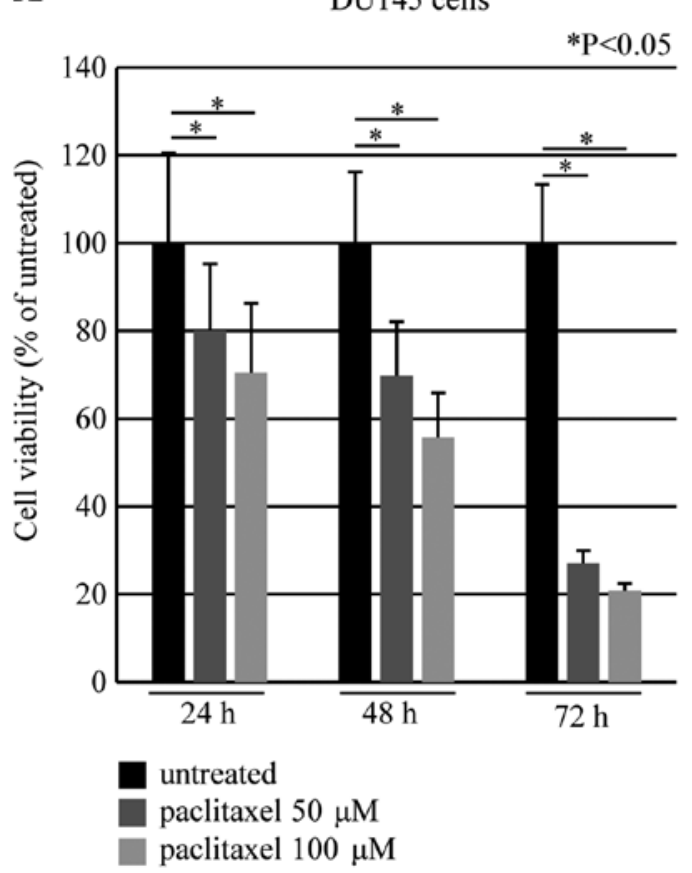

B

PC-3 cells

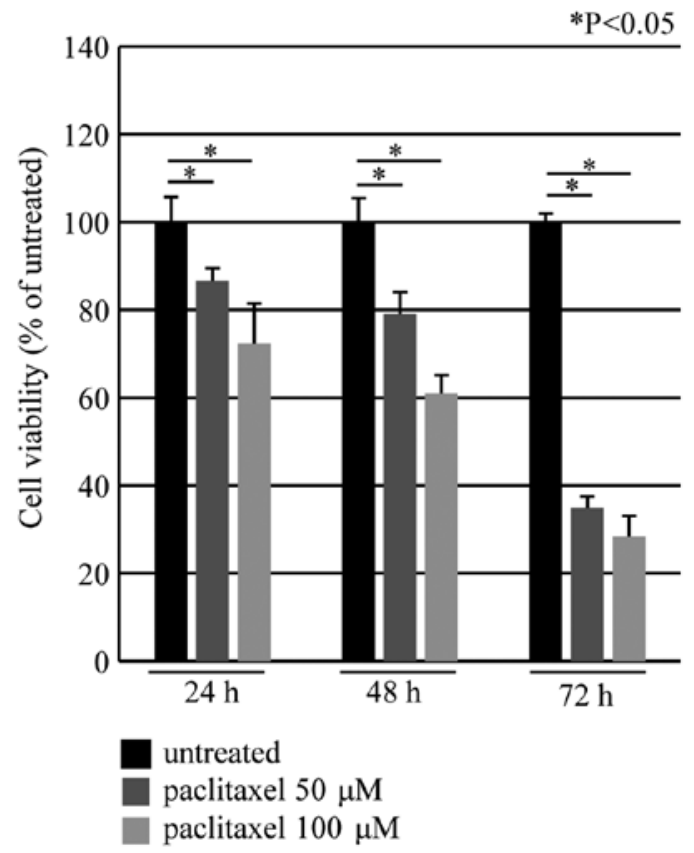

Figure 4. Paclitaxel-induced time- and dose-dependent cell death in DU145 and PC-3 cells. The cells were treated with 50 or $100 \mu \mathrm{M}$ of paclitaxel for 24,48 and $72 \mathrm{~h}$, and cell viability was measured using the MTS-assay in (A) DU145 and (B) PC-3 cells. The values are shown as a percentage of each control. Each value represents the mean \pm SEM (bars) of three independent experiments $\left({ }^{*} \mathrm{P}<0.05\right.$, compared with the untreated). MTS, [3-(4,5-dimethylthiazol-2-yl)5-(3-carboxymethoxyphenyl)-2-(4-sulfophenyl)-2H-tetrazolium].

$\mathbf{A}$

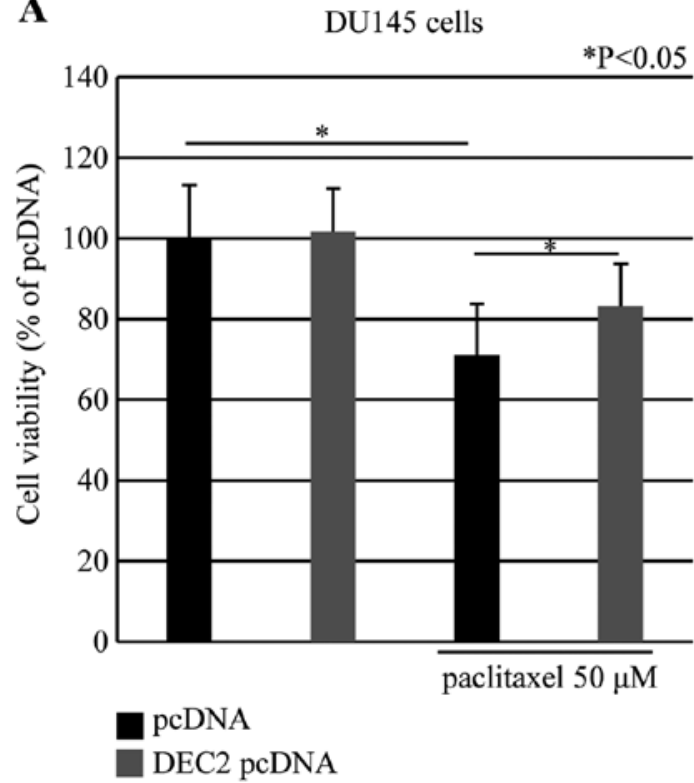

B

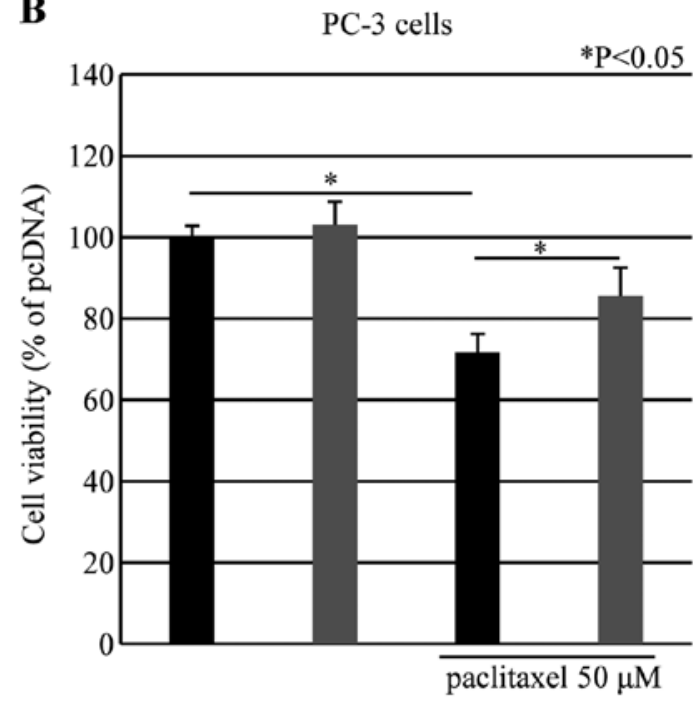

pcDNA

DEC2 pcDNA

Figure 5. DEC2 overexpression inhibits cell death induced by paclitaxel in DU145 and PC-3 cells. DU145 or PC-3 cells transfected with DEC2 pcDNA were treated with or without $50 \mu \mathrm{M}$ of paclitaxel for $24 \mathrm{~h}$. Cell viability was measured using the MTS assay in (A) DU145 and (B) PC-3 cells. The values are shown as a percentage of the control. Each value is the mean \pm SEM (bars) of three independent experiments ( ${ }^{*} \mathrm{P}<0.05$, compared with the control pcDNA). DEC2, differentiated embryonic chondrocyte 2; MTS, [3-(4,5-dimethylthiazol-2-yl)-5-(3-carboxymethoxyphenyl)-2-(4-sulfophenyl)-2H-tetrazolium].

an unstable effect on the expression of apoptotic markers. Since proteins exert their functions only at optimal concentrations, this may provide a more plausible explanation for the fact that the results of overexpression treatment were not consistent with those of the knockdown treatment.
In conclusion, the results of the present study confirm the anti-apoptotic character of DEC2 in paclitaxel-induced apoptosis, in two prostate adenocarcinoma cell lines. In addition to DU145 and PC-3 cell lines, DEC2 has been shown to inhibit apoptosis in breast carcinoma MCF-7 cells (17) oral squamous 
cell carcinoma HSC-3 cells (25), and esophageal squamous cell carcinoma (ESCC) TE-11 cells (article accepted). Inhibitor of DEC2 may be developed and be used as one of the choices when conferring CRPC in clinical chemotherapy in the future.

\section{Acknowledgements}

The present study was supported by Grants-in-Aid for Science from the Ministry of Education, Culture, Sports, Science and Technology of Japan; a grant for Hirosaki University Institutional Research; and the Fund for the Promotion of International Scientific Research.

\section{References}

1. Siegel R, Ma J, Zou Z and Jemal A: Cancer statistics, 2014. CA Cancer J Clin 64: 9-29, 2014.

2. Debes JD and Tindall DJ: Mechanisms of androgen-refractory prostate cancer. N Engl J Med 351: 1488-1490, 2004.

3. Tannock IF, de Wit R, Berry WR, Horti J, Pluzanska A, Chi KN, Oudard S, Théodore C, James ND, Turesson I, et al; TAX 327 Investigators: Docetaxel plus prednisone or mitoxantrone plus prednisone for advanced prostate cancer. N Engl J Med 351: 1502-1512, 2004.

4. Petrylak DP1, Tangen CM, Hussain MH, Lara PN Jr, Jones JA, Taplin ME, Burch PA, Berry D, Moinpour C, Kohli M, et al: Docetaxel and estramustine compared with mitoxantrone and prednisone for advanced refractory prostate cancer. N Engl J Med: 351: 1513-1520, 2004.

5. Kelly WK, Curley T, Slovin S, Heller G, McCaffrey J, Bajorin D, Ciolino A, Regan K, Schwartz M, Kantoff P, et al: Paclitaxel, estramustine phosphate, and carboplatin in patients with advanced prostate cancer. J Clin Oncol 19: 44-53, 2001.

6. McGuire WP, Rowinsky EK, Rosenshein NB, Grumbine FC, Ettinger DS, Armstrong DK and Donehower RC: Taxol: A unique antineoplastic agent with significant activity in advanced ovarian epithelial neoplasms. Ann Intern Med 111: 273-279, 1989.

7. Rowinsky EK, Burke PJ, Karp JE, Tucker RW, Ettinger DS and Donehower RC: Phase I and pharmacodynamic study of taxol in refractory acute leukemias. Cancer Res 49: 4640-4647, 1989.

8. Sunters A, Madureira PA, Pomeranz KM, Aubert M, Brosens JJ, Cook SJ, Burgering BM, Coombes RC and Lam EW: Paclitaxelinduced nuclear translocation of FOXO3a in breast cancer cells is mediated by c-Jun NH2-terminal kinase and Akt. Cancer Res 66: 212-220, 2006.

9. Kolomeichuk SN, Terrano DT, Lyle CS, Sabapathy K and Chambers TC: Distinct signaling pathways of microtubule inhibitors-vinblastine and Taxol induce JNK-dependent cell death but through AP-1-dependent and AP-1-independent mechanisms, respectively. FEBS J 275: 1889-1899, 2008.

10. TudorG,AguileraA,HalversonDO,LaingNDandSausvilleEA: Susceptibility to drug-induced apoptosis correlates with differential modulation of Bad, Bcl-2 and Bcl-xL protein levels. Cell Death Differ 7: 574-586, 2000.

11. Lim SJ, Choi MK, Kim MJ and Kim JK: Alpha-tocopheryl succinate potentiates the paclitaxel-induced apoptosis through enforced caspase 8 activation in human H460 lung cancer cells. Exp Mol Med 41: 737-745, 2009.
12. Saunders DE, Lawrence WD, Christensen C, Wappler NL, Ruan H and Deppe G: Paclitaxel-induced apoptosis in MCF-7 breast-cancer cells. Int J Cancer 70: 214-220, 1997.

13. Sun H and Taneja R: Stra13 expression is associated with growth arrest and represses transcription through histone deacetylase (HDAC)-dependent and HDAC-independent mechanisms. Proc Natl Acad Sci USA 97: 4058-4063, 2000.

14. Honma S, Kawamoto T, Takagi Y, Fujimoto K, Sato F, Noshiro M, Kato Y and Honma K: Dec1 and Dec2 are regulators of the mammalian molecular clock. Nature 419: 841-844, 2002.

15. Chakrabarti J, Turley H, Campo L, Han C, Harris AL, Gatter KC and Fox SB: The transcription factor DEC1 (stra13, SHARP2) is associated with the hypoxic response and high tumour grade in human breast cancers. Br J Cancer 91: 954-958, 2004.

16. Li Y, Xie M, Yang J, Yang D, Deng R, Wan Y and Yan B: The expression of antiapoptotic protein survivin is transcriptionally upregulated by DEC1 primarily through multiple spl binding sites in the proximal promoter. Oncogene 25: 3296-3306, 2006.

17. Wu Y, Sato F, Bhawal UK, Kawamoto T, Fujimoto K, Noshiro M, Morohashi S, Kato Y and Kijima H: Basic helix-loop-helix transcription factors DEC1 and DEC2 regulate the paclitaxelinduced apoptotic pathway of MCF-7 human breast cancer cells. Int J Mol Med 27: 491-495, 2011.

18. Liu Y, Sato F, Kawamoto T, Fujimoto K, Morohashi S, Akasaka H, Kondo J, Wu Y, Noshiro M, Kato Y, et al: Anti-apoptotic effect of the basic helix-loop-helix (bHLH) transcription factor DEC2 in human breast cancer cells. Genes Cells 15: 315-325, 2010.

19. Wu Y, Sato H, Suzuki T, Yoshizawa T, Morohashi S, Seino H, Kawamoto T, Fujimoto K, Kato Y and Kijima H: Involvement of $\mathrm{c}-\mathrm{Myc}$ in the proliferation of MCF-7 human breast cancer cells induced by bHLH transcription factor DEC2. Int J Mol Med 35: 815-820, 2015.

20. Lee JT, Jr, Steelman LS and McCubrey JA: Phosphatidylinositol 3'-kinase activation leads to multidrug resistance protein-1 expression and subsequent chemoresistance in advanced prostate cancer cells. Cancer Res 64: 8397-8404, 2004.

21. Thin TH, Li L, Chung TK, Sun H and Taneja R: Stra13 is induced by genotoxic stress and regulates ionizing-radiation-induced apoptosis. EMBO Rep 8: 401-407, 2007.

22. Miyazaki K, Kawamoto T, Tanimoto K, Nishiyama M, Honda H and Kato Y: Identification of functional hypoxia response elements in the promoter region of the DEC1 and DEC2 genes. J Biol Chem 277: 47014-47021, 2002.

23. Yamada K, Kawata H, Shou Z, Mizutani T, Noguchi T and Miyamoto $\mathrm{K}$ : Insulin induces the expression of the SHARP-2/Stra13/DEC1 gene via a phosphoinositide 3-kinase pathway. J Biol Chem 278: 30719-30724, 2003.

24. Kon N, Hirota T, Kawamoto T, Kato Y, Tsubota T and Fukada Y: Activation of TGF-beta/activin signalling resets the circadian clock through rapid induction of Dec1 transcripts. Nat Cell Biol 10: 1463-1469, 2008.

25. Wu Y, Sato F, Bhawal UK, Kawamoto T, Fujimoto K, Noshiro M, Seino H, Morohashi S, Kato Y and Kijima H: BHLH transcription factor DEC2 regulates pro-apoptotic factor Bim in human oral cancer HSC-3 cells. Biomed Res 33: 75-82, 2012.

26. Wu Y, Sato F, Yamada T, Bhawal UK, Kawamoto T, Fujimoto K, Noshiro M, Seino H, Morohashi S, Hakamada K, et al: The BHLH transcription factor DEC1 plays an important role in the epithelial-mesenchymal transition of pancreatic cancer. Int $\mathrm{J}$ Oncol 41: 1337-1346, 2012. 